J. Lake Sci. (湖泊科学) , 2017, 29(6): 1359-1371

DOI 10. 18307/2017. 0608

(C) 2017 by Journal of Lake Sciences

\title{
珠江流域氮、磷营养盐入河量估算及预测”
}

\author{
徐 鹏 ${ }^{1}$, 林永红 ${ }^{2}$,杨顺顺 ${ }^{3}$, 栾胜基 ${ }^{1,2}$ ** $^{2}$ \\ (1: 北京大学环境科学与工程学院, 北京 100871) \\ (2: 北京大学深圳研究生院环境与能源学院, 深圳 518055) \\ (3: 湖南省社会科学院, 长沙 410003)
}

\begin{abstract}
摘 要: 针对日益严重的流域营养盐污染问题, 以珠江流域为例,采用系统动力学模型与多主体农户和农村环境管理模 型耦合构建反映农户生产决策实际污染过程的流域氮、磷营养盐排放仿真系统, 模拟 2000-2030 年不同污染源的营养盐 产生、排放和进人河流的污染过程, 分析其污染特征、影响因素和演变趋势. 结果表明: 在基准情境下, 珠江流域总氮( TN) 人河量从 2000 年的 $5.79 \times 10^{5} \mathrm{t}$ 增加到 2030 年 $9.45 \times 10^{5} \mathrm{t}$, 在 2027 年达到峰值 $\left(9.53 \times 10^{5} \mathrm{t}\right)$; 总磷 ( TP ) 人河量逐年递增, 年均增长率为 $2.0 \%$, 从 2000 年的 $7.9 \times 10^{4} \mathrm{t}$ 增加到 2030 年 $1.4 \times 10^{5} \mathrm{t}$. 在 TN 人河量中, 种植业贡献最多, 其次是城镇污 水、养殖业和农村污水, 2000-2030 年期间年均贡献率相应为 43.5\%、32.5\%、19.2\% 和 4.9\% . 在 TP 人河量中, 2000- 2030 年种植业、养殖业、城镇污水和农村污水的年均贡献比例分别为 $35.6 \% 、 28.8 \% 、 21.5 \%$ 和 $14.1 \% ; 2000-2010$ 年, 养殖业为 第一污染源, 其次是种植业、城镇污水和农村污水;2011 年种植业的贡献比例 (31.6\%) 开始超过养殖业 (30.8\%) 成为首要 污染. 研究显示, 流域营养盐排放仿真系统可为营养盐控制提供技术支持和理论依据.
\end{abstract}

关键词: 珠江流域; 营养盐; 模型耦合; 人河量; 未来预测

\section{Input load to river and future projection for nitrogen and phosphorous nutrient controlling of Pearl River Basin}

\author{
XU Peng ${ }^{1}$, LIN Yonghong ${ }^{2}$, YANG Shunshun ${ }^{3} \&$ LUAN Shengji ${ }^{1,2 * *}$ \\ (1: College of Environmental Sciences and Engineering, Peking University, Beijing 100871, P.R.China) \\ (2: School of Environment and Energy, Peking University Shenzhen Graduate School, Shenzhen 518055, P.R. China) \\ (3: Hunan Academy of Social Sciences, Changsha 410003, P.R.China)
}

Abstract: In view of the increasing serious watershed nutrient pollution, simulation system of watershed nutrient pollution with cou-
pling System Dynamic model with Multi-agent Agricultural household model for Rural Environmental Management model was estab-
lished to reflect the practical pollution process of farmers' production decision; The nitrogen and phosphorus nutrient generation, e-
mission and pollution process of arriving rivers from various emission sources were simulated from 2000 to 2030 , and the pollution
characteristics, influencing factors and evolution trends were analyzed. This research took Pearl River Basin as the research object.
Under the business as usual scenario, the results indicated that the total nitrogen ( TN) input to Pearl River Basin fluctuated with
one peak in 2027 ( $9.53 \times 10^{5} \mathrm{t}$ ), and increased from $5.79 \times 10^{5}$ to $9.45 \times 10^{5} \mathrm{t}$ during the period of $2000-2030$. Total phosphorus
( TP) input to Pearl River Basin increased from $7.9 \times 10^{4}$ to $1.4 \times 10^{5} \mathrm{t}$ at an average annual rate of $2.0 \%$ during the period of
$2000-2030$. Among the various sources of TN input, planting industry was the largest contributor, followed by municipal sewage,
livestock and poultry breeding, and rural domestic wastewater; Their average annual contributions were approximately $43.5 \%$,
$32.5 \%$, $19.2 \%$ and $4.9 \%$, respectively. Among the various sources of TP input, the average annual contributions of planting in-
dustry, livestock and poultry breeding, municipal sewage and rural domestic wastewater were approximately $35.6 \%, 28.8 \%$,
$21.5 \%$ and $14.1 \%$ over the period of $2000-2030$, respectively; The livestock and poultry breeding was the largest emitter, followed

* 国际科技合作专项(2012DFG92020)、湖南省哲学社会科学基金项目(13YBB139)和湖南省自然科学基金青年项目 (2015JJ3083) 联合资助. 2016-12-08 收稿; 2017-04-10 收修改稿. 徐鹏 (1989 ), 男, 博士研究生; E-mail: xupenglzl@ pku.edu.cn. 林永红(1990 ) (并列第一作者), 女, 硕士研究生;E-mail: syhlin@163.com.

** 通信作者;E-mail:luansj@ pkusz.edu.cn. 
by planting industry, municipal sewage and rural domestic wastewater from 2000 to 2010; In 2011, the contribution of planting industry $(31.6 \%)$ has begun to exceed livestock and poultry breeding $(30.8 \%)$, and planting industry became as primary pollution source. Research showed that the simulation system of watershed nutrient pollution can provide technical support and theoretical basis for controlling nutrients.

Keywords: Pearl River Basin; nutrient; model coupling; input load to river; future projection

随着我国农业现代化进程的不断加速, 大面积过度使用化肥和农药、畜禽养殖粪便无序排放造成农业 非点源污染加剧,致使我国内陆主要河流和近海水域普遍面临富营养化严重、蓝藻水华灾害频发、水质恶化 和水生生态系统遭到破坏 ${ }^{[1-3]}$. 据《全国第一次污染源普查公报》显示: 2007 年我国农业源 TN 和 TP 流失量 分别为 $2.62 \times 10^{6}$ 和 $2.69 \times 10^{5} \mathrm{t}$, 占相应总流失量的 $55.5 \%$ 和 $63.6 \%{ }^{[4]}$. 在未来几十年, 由于我国人口和城镇化 率不断增加, 粮食和肉、蛋、奶的需求增大将加剧氮、磷营养盐的输人强度, 使地表水环境恶化趋势更加严 峻 ${ }^{[5-8]}$. 因此, 有必要开展流域氮、磷营养盐负荷现状水平和未来演变趋势的估算, 识别主要驱动因素, 以此 来指导实现流域氮、磷营养盐污染的控制.

珠江是中国南方最大的河流. 珠江流域由西江、北江、东江和珠江三角洲水系组成,覆盖滇、黔、桂、粤 4 省区, 自从 1970s 改革开放以来,在我国的社会经济发展中有着举足轻重的作用 ${ }^{[9]}$. 珠江具有高的营养盐浓 度,Tong 等 ${ }^{[10]}$ 通过估算中国主要河流营养盐进人沿海水域的负荷, 2012 年珠江对 TN 和 TP 分别贡献约 $26 \%(0.8 \mathrm{Tg})$ 和 $12 \%$ ( $0.03 \mathrm{Tg}$ ), 仅次于最大贡献源长江. 已有一些研究关注珠江流域氮、磷营养盐污染问题. Huang 等 ${ }^{[11]}$ 于 1998 年对珠江口水质监测发现, 河流营养盐输送过程对珠江口水体营养盐浓度具有重要贡 献. Ti 等 ${ }^{[12]}$ 利用 $1980-2010$ 年省域尺度的社会活动数据估算珠江流域河流氮输出到沿海水域的量增大了 3.0 倍, 控制情景下 (实施肥料管理和污水处理等一些减排措施) 2050 年的河流氮输出量相比基准情景 (人 口经济增长,无污水控制) 将减少 2.3 倍. Strokal 等 ${ }^{[13]}$ 利用 Global NEWS ( Nutrient Export from WaterSheds) model 估算从 1970-2050 年珠江溶解性无机氮、磷对沿海水域的输人量将会增加 $2.0 \sim 2.5$ 倍, $2 / 3$ 来源于东 江和珠江三角洲. 但以往研究仍存在以下几个方面的不足: (1)大多只考虑化肥施用和城镇化等人类活动的 影响以及利用省域尺度数据 ${ }^{[14-15]}$; 2)多采用 Global NEWS 模型中的数据进而会增加排放的不确定性 ${ }^{[16-19]}$; (3)很少探讨从微观角度对宏观排放的影响 ${ }^{[20-21]}$. 本研究为了更加准确地定量描述不同排放源营养盐负荷的 变化趋势, 分别针对以上不足进行了改进: (1)全面考虑营养盐排放源和采用市域尺度社会活动数据; (2)选择 具有空间分异性的本土化修正因子和参数; (3)通过系统动力学 (System Dynamics, SD) 模型和多主体农户和 农村环境管理模型 (Multi-agent Agricultural household model for Rural Environmental Management model, MAREM) 耦合, 定量描述农户个体行为对流域营养盐污染的影响.

$\mathrm{SD}$ 在研究复杂系统的行为和处理非线性、高阶次、多变量、多重反馈问题方面具有独特的优势, 模型通 过系统内部各变量之间的反馈约束 (正反馈和负反馈) , 从而模拟整个系统的行为变化与动态响应关系 ${ }^{[22]}$. 目前, SD 方法的引人为流域社会经济和水环境的复杂反馈关系的模拟提供了新的方法与思路, 主要是由于 系统动力学模型具有强大的系统分析功能和对未来的预测能力, 并且可实现与其它模型的耦合, 通过模拟 和优化的手段实现了社会经济发展对水环境影响的定量计算, 从而在国内外各类流域社会经济发展对水环 境影响效应决策中得到广泛的应用 ${ }^{[23-26]}$. 此外,农业非点源受农业管理措施、农户生产行为和农业政策等因 素的影响, 其中, 制定和实施合理的农业政策是控制农业非点源营养盐污染的重要手段; 农业政策通过引导 农户生产行为会对流域营养盐排放产生调控作用 ${ }^{[27]}$, MAREM 模型的引人则能够模拟农户在不同农业政策 下的生产行为, 目前农业政策主要包括命令型工具 (农场耕作和畜禽养殖管理规定、最佳管理措施导则等) 和经济型工具( 税收、补贴政策等). 据此, 本研究以珠江流域为例, 通过 SD 模型和 MAREM 耦合构建反映农 户生产决策实际污染过程的流域营养盐排放仿真系统, 模拟 2000-2030 年珠江各大支流进人干流的不同污 染源的氮、磷营养盐 (即人河量) 产生、排放和进人河流的污染过程, 分析其现状水平及未来演变趋势的污染 特征、影响因素和相关农业控制政策, 以期为流域营养盐污染治理提供技术支持和理论依据. 


\section{1 材料与方法}

\section{1 研究区域概况}

珠江流域 $\left(21^{\circ} 31^{\prime} \sim 26^{\circ} 49^{\prime} \mathrm{N}, 102^{\circ} 14^{\prime} \sim 115^{\circ} 53^{\prime} \mathrm{E}\right.$ ) (图 1), 发育于云贵高原南侧, 是中国第三大流域, 集 水面积 $4.537 \times 10^{5} \mathrm{~km}^{2}$. 珠江流域地处亚热带季风气候区, 年平均降水量和平均气温分别为 $1200 \sim 2200 \mathrm{~mm}$ 和 $14 \sim 22^{\circ} \mathrm{C}$; 年平均降水量由东部沿海地区向西部山区递减 ${ }^{[28]}$, 地势西北高、东南低; 年内降水多集中在 49 月,约占全年降水量的 70\% 85\%. 西江作为珠江流域的最大支流, 河流总长为 $2214 \mathrm{~km}$, 其后依次是北江、 东江和珠江三角洲, 分别占珠江流域总面积的 $77.8 \% 、 10.4 \% 、 5.9 \%$ 和 $5.9 \%{ }^{[9]} .2012$ 年, 珠江流域的水质状况 很好, 全年流域 I III 类水比例占 $83.2 \%$; 但是相比之下, 流域部分二级分区如南北盘江、东江和珠江三角洲 的水质较差, 河流水质为 I III类的比例分别占 $75.2 \% 、 68.4 \%$ 和 $63.9 \%$, 而红柳江、郁江、西江和北江的水质 较好, 河流水质为 I III 类的比例分别占 $92.1 \% 、 96.7 \% 、 91.2 \%$ 和 $97.5 \%$ ( http ://www.pearlwater.gov.cn/xxcx/ szygg/13gb/t20150722_64761.htm).

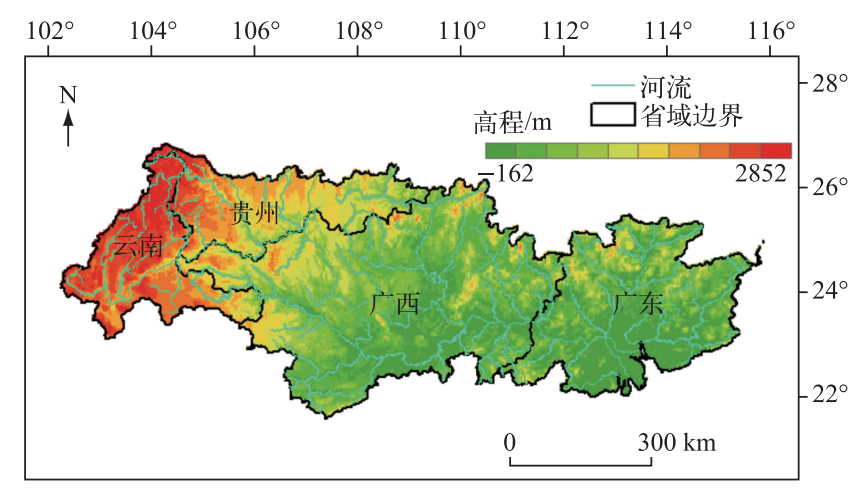

图 1 珠江流域图

Fig.1 Sketch map of the Pearl River Basin

\subsection{SD 仿真模型}

珠江流域营养盐污染系统是一个涉及人口、社会、经济、环境、资源和生产活动等因素的复杂系统. 珠江 流域营养盐污染源主要包括农业、工业、城镇生活和农村生活污染源等, 据此, 本研究将珠江流域营养盐污 染复合系统划分为农业生产污染、城镇点源污染和农村生活污染 3 个子系统, 这 3 个子系统均是人口、资源、 环境与经济活动的综合集成,各子系统之间存在密切的相互作用,共同构成一个复杂的动态反馈系统. 农业 生产污染子系统主要包含种植业和养殖业生产系统, 两个生产系统通过农田进行能量和物质的传递, 整个 生产过程中养分流失途径有畜禽粪便在储存或堆肥过程中产生的径流损失、畜禽粪尿通过沼气工程处理后 排放的点源污染、未经任何处理直接排放的畜禽粪尿污染、有机肥和化肥施用后的农田径流流失以及农作 物收获后产生的残体污染. 城镇点源污染子系统中污水类型包括城镇生活污水和工业污水, 流域人口与经 济发展水平决定其污染物排放量,城市污水处理设施也会对点源污染物削减产生影响; 同时, 该子系统通过 农业生产产值与农业生产污染子系统发生联系. 在农村生活污染子系统中, 由于农村缺乏污水收集管道以 及处理设施, 污染物排放总量直接与农村人口总量密切相关; 流域城镇化发展, 农村人口与城镇人口具有一 定的比例关系, 且农村人口作为主要劳动力参与农业生产活动, 故该子系统通过城镇和农村人口分布情况 与农村生活污染子系统发生联系, 通过劳动力投人和农业生产要素与农业生产污染子系统发生联系. 基于 以上分析, 本研究构建一个复杂的动态反馈系统, 提出了珠江流域营养盐污染概念模型 (图 2). 本研究以 VensimDSS $^{\circledR}$ (Ventana Simulation Environment Decision Support System) 软件作为建立模型和模拟仿真的平台, 通过对珠江流域营养盐污染概念模型进行量化, 将其转化为主导结构模型 (图 3).

1.2.1 模型边界以珠江流域边界为模型边界, 涉及 4 省 28 个市. 基准年为 2012 年, 规划年为 2030 年, 模拟 时间间隔为 1 年. 


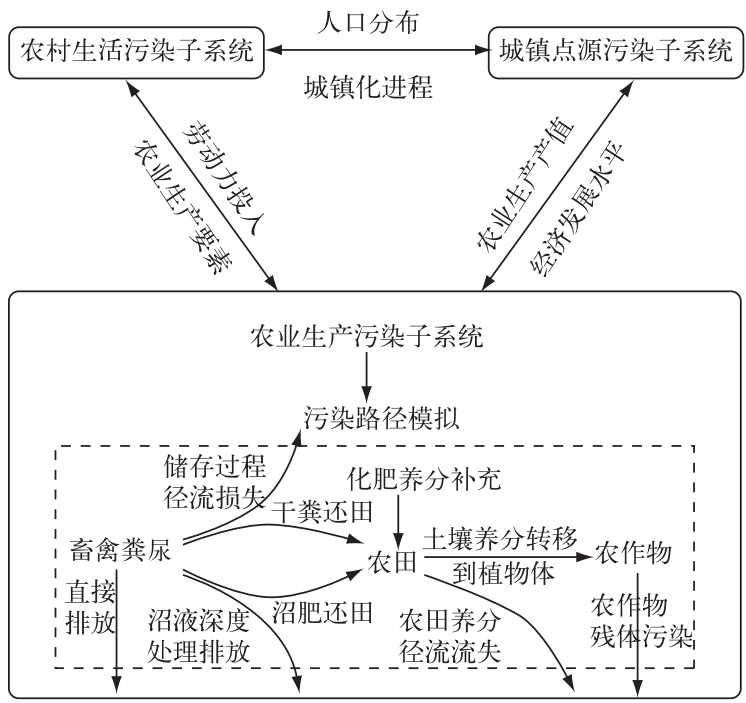

图 2 珠江流域营养盐污染系统概念模型

Fig. 2 Conceptual model of Nutrient Pollution in the Pearl River Basin

1.2.2 系统及变量设置 本研究从反映农户生产决策实际污染过程角度构建了珠江流域营养盐污染 SD 仿 真模型, 并在农业种植和畜禽养殖子系统中耦合 MAREM 模型来体现农户个体行为, 关于 MAREM 模型介绍 及参数选取参考徐鹏等 ${ }^{[29]}$. SD 模型主要变量有 4 种: 状态变量、速率变量、辅助变量和常数变量. 珠江流域 营养盐污染 SD 仿真模型包括 52 个变量, 其中状态变量 7 个、速率变量 7 个和辅助变量 38 个. 变量赋值的 基本方法有规划设定法、统计学方法和模型校正法 ${ }^{\left[{ }^{[0]}\right.}$. 由于不同变量的性质不同,对不同变量采用的统计 方法应有所区别. 本研究根据变量自身性质和模型运行要求, 综合运用了 3 种方法, 即依据当地的统计数 据、对珠江流域的北江和东江的现场监测和农户访谈数据 ${ }^{[31-33]}$ 、社会经济和资源发展规划等数据来确定珠 江流域营养盐污染 SD 仿真模型系统的待定参数. 本研究假设在模拟时间段内,珠江流域的气温、降水、热 量、径流、地质等自然因素与历史平均水平保持一致, 社会经济发展按照历史水平和规划发展, 居民污水处 理水平、农业管理方式、产业结构调整等人为因素则随着社会发展而不断发生改变,以便分析和讨论引起流 域营养盐污染的社会因素以及评估针对农户的污染控制政策效果,此情景为基准情景. 由于篇幅有限,本文 仅列出部分主要环境参数值 (表 1 ) 和重要变量方程 (表 2 ).

1.2.3 模型检验 目前广泛采用的 SD 模型有效性检验方法有参数敏感度检验、直观检验以及历史检验 ${ }^{[51]}$. 一般来说, 模型只要能够正确反映实相的行为, 符合实际调查结果或统计结果就认为模型是有效的 ${ }^{[52]}$. 本 研究在建立 SD 模型时,首先确定模型的目的、边界、适用性、物理结构和政策变量等方面,之后利用历史检 验法验证所建立模型的有效性, 以珠江流域 2000-2012 年有关的实际数据作为历史变量, 预测相应年份的 数据, 并通过误差分析方法比较历史值和预测结果, 各变量的历年平均相对误差 (绝对值) 越小, 说明所建立 的 SD 模型能有效代表实际系统, 模拟的结果具有可靠性和准确性. 由表 3 可以看出,模型中所有历史变量 的模拟值和实际值的历年平均相对误差 (绝对值) 均小于 $10 \%$, 珠江流域营养盐污染 SD 模型对历史数据模 拟效果较好,能够有效代表实际系统,可用于珠江流域营养盐污染的模拟和预测.

1.2.4 数据来源 主要数据来源为广东、广西、贵州和云南 4 省及流域内 28 个市 2000- 2013 年统计年鉴、水 资源公报、水环境公报、环境统计数据、中国农业统计资料、污染源普查数据, 以及地方不同部门的规划, 或 者珠江流域的现场监测和农户访谈数据;此外,部分数据参考文献 [34-50]. 


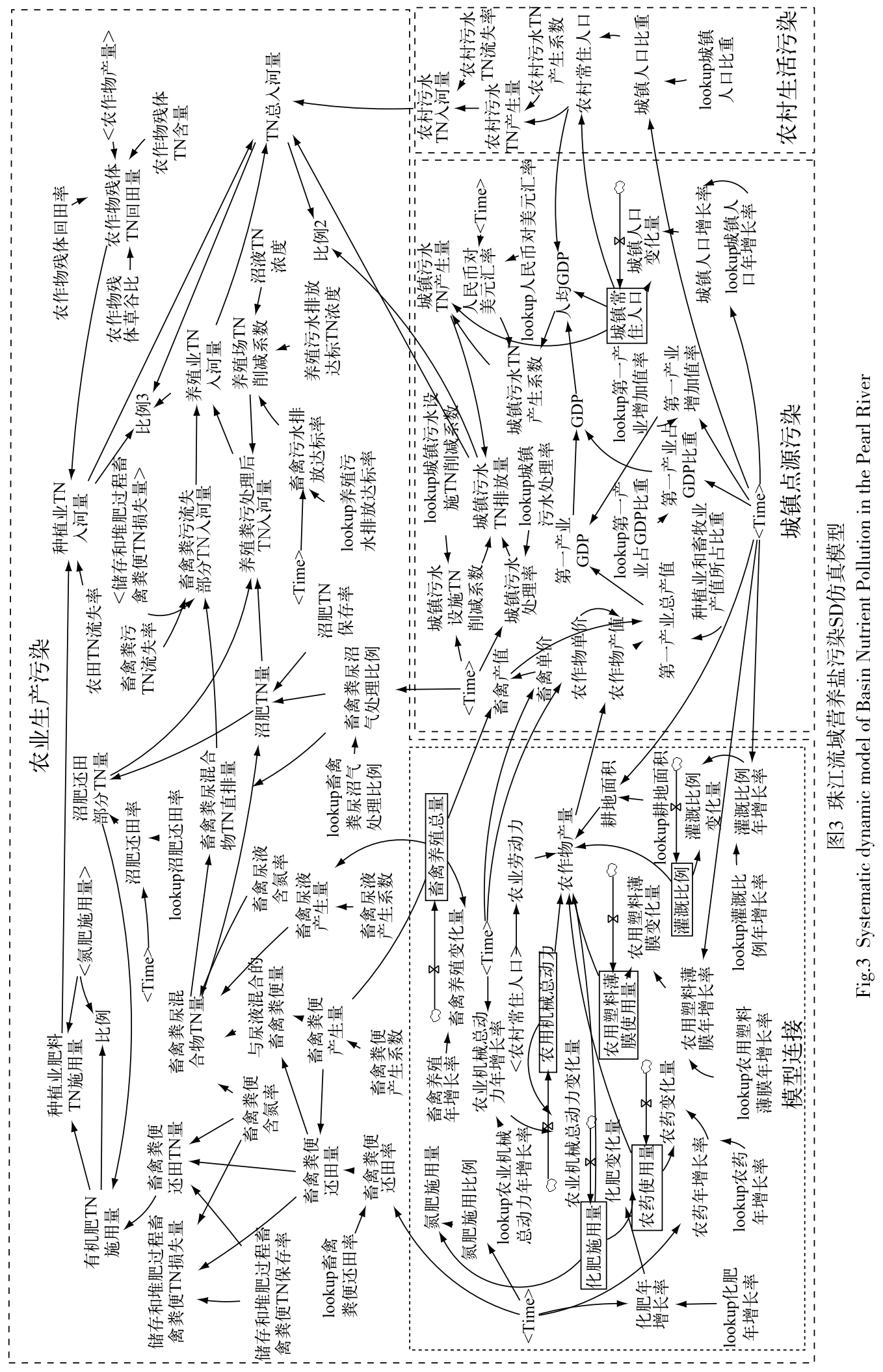


表 1 珠江流域营养盐污染 SD 仿真模型主要参数值

Tab.1 Main parameters of SD model of Nutrient Pollution in the Pearl River Basin

\begin{tabular}{|c|c|c|}
\hline 变量 & 变量初始值 & 变量来源 \\
\hline 城镇人口年增长率 & With lookup ( time) & 城镇人口增长速度, 2000-2012 年数据 \\
\hline 城镇人口比重 & With lookup ( time) & 城镇人口结构, 2000-2012 年数据 \\
\hline 第一产业占 GDP 比重 & With lookup ( time) & 农业农村经济发展状况, 2000-2012 年数据 \\
\hline 畜禽养殖年增长率 & 0.0122 & 畜禽养殖增长速度( 2000－2012 年平均值) \\
\hline 储存和堆肥过程畜禽粪便 TN、TP 保存率 & $0.6 、 0.7$ & 参考文献 [34-36] \\
\hline 沼肥 TN、TP 保存率 & $0.6713,0.82$ & 参考文献 [34-35,37-38 ] \\
\hline 沼液 TN、TP 浓度 & $550,77.1$ & $\mathrm{mg} / \mathrm{L}$,参考文献 [ 38-40 ] \\
\hline 养殖污水排放达标 TN 、TP 浓度 & $89.29 、 11.5$ & $\mathrm{mg} / \mathrm{L}$,参考文献[38-39] \\
\hline 农作物残体 TN 含量 & 0.007 & kg N/kg 干物质,参考文献[41] \\
\hline 农作物残体 TP 含量 & 0.002 & kg P/kg 干物质,参考文献 [41] \\
\hline 农村污水 TN、TP 产生系数 & $10.0 、 1.0$ & $\begin{array}{l}\mathrm{g} /(\text { 人 } \cdot \mathrm{d}) \text {, 数据来源于《第一次全国污染源普 } \\
\text { 查城镇生活源产排物系数手册》 }\end{array}$ \\
\hline 城镇污水 TN 产生系数 & $\begin{array}{l}8+11 \text { ( 人均 GDP/人民币对 } \\
\text { 美元汇率/ } 43639 \times 1.5)^{0.5}\end{array}$ & g/ (人・d),参考文献[42］ \\
\hline 城镇污水 TP 产生系数 & With lookup ( time) & $\begin{array}{l}\mathrm{g} /(\text { 人 } \cdot \mathrm{d}) \text {, 数据来源于《第一次全国污染源普 } \\
\text { 查城镇生活源产排物系数手册》 }\end{array}$ \\
\hline 城镇污水处理率 & With lookup ( time) & $\begin{array}{l}\text { 随着珠江流域城市污水处理力度的加大, 城镇 } \\
\text { 污水处理率会逐渐提高, } 2000-2012 \text { 年数据 }\end{array}$ \\
\hline 城镇污水设施 TN、TP 削减系数 & With lookup ( time) & $\begin{array}{l}\text { 城镇污水进人污水处理厂后削减比例, 参考《城 } \\
\text { 镇污水处理厂污染物排放标准》( GB } 18918- \\
2002) \text { 和《污水排人城镇下水道水质标准》( GB/T } \\
31962-2015)\end{array}$ \\
\hline 农田 TN、TP 流失率 & $0.15,0.05$ & 参考文献 [ 43-45 ] \\
\hline 畜禽粪污 TN、TP 流失率 & $0.3 、 0.175$ & 参考文献[37,44,46] \\
\hline 农村污水 TN、TP 流失率 & $0.21 、 0.475$ & 参考文献[47-50] \\
\hline
\end{tabular}

* With lookup (time) 表示将城镇人口年增长率、城镇人口比重、第一产业占 GDP 比重、城镇污水 TP 产生系数、城镇污水 处理率和城镇污水设施 TN 、 TP 削减系数分别设为仿真时间的表函数.

表 2 珠江流域营养盐污染 SD 仿真模型重要变量方程

Tab.2 Main equations of SD model of Nutrient Pollution in the Pearl River Basin

\begin{tabular}{|c|c|}
\hline 变量 & 方程 \\
\hline 种植业 TN 人河量 & $\begin{array}{l}\text { (氮肥施用量+沼肥还田部分 TN 量+畜禽粪便还田 TN 量+农作物残体 TN 回田 } \\
\text { 量)农田 TN 流失率 }\end{array}$ \\
\hline 农作物残体 TN 回田量 & 农作物产量×农作物残体草谷比×农作物残体 TN 含量×农作物残体回田率 \\
\hline 农作物产量 & 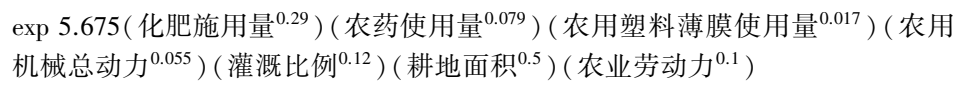 \\
\hline 养殖业 TN 人河量 & $\begin{array}{l}\text { (畜禽粪尿混合物 } \mathrm{TN} \text { 直排量+储存和堆肥过程畜禽粪便 } \mathrm{TN} \text { 损失量) 畜禽粪污 } \\
\mathrm{TN} \text { 流失率 }+(\text { 沼肥 } \mathrm{TN} \text { 量-沼肥还田部分 } \mathrm{TN} \text { 量) (1-养殖场 } \mathrm{TN} \text { 削减系数) }\end{array}$ \\
\hline 畜禽粪尿混合物 TN 直排量 & 畜禽粪尿混合物 TN 量(1-畜禽粪尿沼气处理比例) \\
\hline 储存和堆肥过程畜禽粪便 $\mathrm{TN}$ 损失量 & 畜禽粪便还田量(1-储存和堆肥过程畜禽粪便 $\mathrm{TN}$ 保存率) 畜禽粪便含氮率 \\
\hline 沼肥 $\mathrm{TN}$ 量 & 畜禽粪尿混合物 TN 量×沼肥 TN 保存率×畜禽粪尿沼气处理比例 \\
\hline 养殖场 TN 削减系数 & (沼液 $\mathrm{TN}$ 浓度-养殖污水排放达标 $\mathrm{TN}$ 浓度 $) \times$ 畜禽污水排放达标率/沼液 $\mathrm{TN}$ 浓度 \\
\hline 城镇污水 TN 人河量 & $\begin{array}{l}\text { 城镇污水 } \mathrm{TN} \text { 产生量 }- \text { 城镇污水 } \mathrm{TN} \text { 产生量 } \times \text { 城镇污水处理率 } \times \text { 城镇污水设施 } \mathrm{TN} \\
\text { 削减系数 }\end{array}$ \\
\hline 农村污水 TN 人河量 & 农村污水 TN 产生量×农村污水 TN 流失率 \\
\hline
\end{tabular}


表 3 珠江流域营养盐污染 SD 仿真系统模拟值与实际值之间的相对误差

Tab.3 The relative error between the simulated and observed values of systematic dynamic model of Nutrient Pollution in the Pearl River Basin

\begin{tabular}{cccc}
\hline 历史变量 & 年平均相对误差 $\%$ 历史变量 & 年平均相对误差 $/ \%$ \\
\hline 农用化肥施用(折纯)量 & 0.39 & 氮肥施用(折纯)量 & 2.10 \\
农药使用量 & 0.56 & 磷肥施用(折纯)量 & 2.79 \\
农用塑料薄膜使用量 & 0.34 & 农作物产值 & 2.37 \\
农业机械总动力 & 0.31 & 畜禽产值 & 7.50 \\
灌溉比例 & 0.61 & GDP & 3.59 \\
耕地面积 & 0 & 城镇常住人口 & 2.45 \\
畜禽养殖总量 & 6.67 & 农村常住人口 & 3.08 \\
\hline
\end{tabular}

\section{2 结果与分析}

\section{1 氮、磷营养盐入河量变化趋势}

珠江流域 TN 人河量从 2000 年的 $5.79 \times 10^{5} \mathrm{t}$ 增加到 2030 年 $9.45 \times 10^{5} \mathrm{t}$, 在 2027 年达到峰值 $\left(9.53 \times 10^{5} \mathrm{t}\right)$ (图 4). 2000-2027 年以年均 1.9\%的速度递增,之后以年均 $0.3 \%$ 的速度递减. 在 TN 人河量中, 2000-2030 年期间种植业贡献最多, 其次是城镇污水、养殖业和农村污水, 年均贡献率分别为 $43.5 \% 、 32.5 \% 、 19.2 \%$ 和 $4.9 \% .2000-2030$ 年, 种植业 TN 人河量逐年增加, 年均增长速度为 $2.6 \% ; 2000-2020$ 年快速增长 (年均增 长速度为 $3.1 \%$ ), 之后以 $1.6 \%$ 的年均增长速度缓慢增加; 种植业 TN 人河量在珠江流域 TN 人河总量中的比 重呈上升趋势, 从 2000 年的 $38.5 \%$ ( 人河量为 $2.23 \times 10^{5} \mathrm{t}$ ) 上升至 2030 年的 $50.4 \%$ (人河量为 $4.77 \times 10^{5} \mathrm{t}$ ). 养殖业 TN 人河量在 2016 年 $\left(1.56 \times 10^{5} \mathrm{t}\right)$ 和 2025 年 $\left(1.56 \times 10^{5} \mathrm{t}\right)$ 出现最大值; 对 TN 人河总量的贡献比例逐 年下降, 年均下降速度为 $1.3 \%$, 贡献比例从 2000 年的 $23.6 \%$ (人河量为 $1.37 \times 10^{5} \mathrm{t}$ ) 下降至 2030 年的 $16.1 \%$ (人河量为 $1.52 \times 10^{5} \mathrm{t}$ ). 城镇污水 TN 入河量在 2024 年达到最大值 $\left(3.16 \times 10^{5} \mathrm{t}\right.$ ), 2000-2024 年以 $2.5 \%$ 的年 均增长速度逐年增加, 之后以 $1.6 \%$ 的年均下降速度递减; 对 $\mathrm{TN}$ 人河总量的贡献比例在 2002 年最小 $\left(29.8 \%\right.$, 人河量为 $\left.1.83 \times 10^{5} \mathrm{t}\right), 2017$ 年达到最大 $\left(34.2 \%\right.$, 人河量为 $\left.2.94 \times 10^{5} \mathrm{t}\right)$. 农村污水 $\mathrm{TN}$ 人河量逐年降 低,年均下降速度为 $1.4 \%$, 从 2000 年的 $4.5 \times 10^{4} \mathrm{t}$ 减少至 2030 年的 $3.0 \times 10^{4} \mathrm{t}$; 而对 $\mathrm{TN}$ 人河总量的贡献比例 也以 $3.0 \%$ 的年均下降速度降低, 从 2000 年的 $7.8 \%$ 降低至 2030 年的 $3.2 \%$.

珠江流域 TP 人河量逐年递增,年均增长速度为 $2.0 \%$,从 2018 年开始缓慢增长; TP 人河量从 2000 年的 $7.9 \times 10^{4} \mathrm{t}$ 增加到 2030 年的 $1.4 \times 10^{5} \mathrm{t}$ (图 4). 在 TP 人河量中, 2000-2030 年种植业、养殖业、城镇污水和农 村污水的年均贡献比例分别为 $35.6 \% 、 28.8 \% 、 21.5 \%$ 和 $14.1 \% ; 2000-2010$ 年, 养殖业为第一污染源, 其次是 种植业、城镇污水和农村污水;2011 年种植业的贡献比例 (31.6\%) 开始超过养殖业 (30.8\%) 成为首要污染 源. 种植业 TP 人河量在 2001 年 $\left(2.0 \times 10^{4} \mathrm{t}\right)$ 达到最低值, 相对于 2000 年下降 $1.3 \%$; 之后, 以 $4.4 \%$ 的年均增 长速度逐年上升, 2030 年达到 $6.7 \times 10^{4} \mathrm{t}$; 种植业 TP 人河量在珠江流域 TP 人河总量中的比重在 2001 年最低 (24.5\%) , 之后至 2030 年逐年递增达到 $47.5 \%$. 养殖业 TP 人河量在 2025 达到最大值 $\left(3.6 \times 10^{4} \mathrm{t}\right), 2000-$ 2025 年以 $1.6 \%$ 的年均增长速度递增, 2026- 2030 年以年均 $0.4 \%$ 的下降速度缓慢降低; $2000-2010$ 年养殖 业为 TP 人河总量的第一贡献源, 之后, 养殖业 TP 人河量在珠江流域 TP 人河总量中的比重以 $1.0 \%$ 的年均 下降速度逐年降低, 低于种植业贡献率位居第二污染源. 城镇污水 TP 人河量在 2024 年达到最大值 $(2.8 \times$ $10^{4}$ t ) ,2000-2024 年以 $2.2 \%$ 的年均增长速度逐年增加, 2005- 2030 年以 $0.9 \%$ 的年均下降速度降低; 对 TP 人河总量的贡献比例在 $18.9 \%$ 22.4\% 范围内波动, 变化不大. 农村污水 TP 人河量逐年减少, 年均下降速度 为 $1.4 \%$, 从 2000 年的 $1.8 \times 10^{4} \mathrm{t}$ 减少至 2030 年的 $1.2 \times 10^{4} \mathrm{t}$; 而对 TP 人河总量的贡献比例也以 $3.2 \%$ 的年均 下降速度降低, 从 2000 年的 $23.2 \%$ 降低至 2030 年的 $8.6 \%$.

\section{2 营养盐污染主要源解析}

种植业氮、磷营养盐污染主要来源于化肥、农作物残体和有机粪肥 (包括堆肥和沼肥). 化学氮肥占种植 业氮污染的比例从 2000 年的 $81.3 \%\left(1.208 \times 10^{6} \mathrm{t}\right)$ 增加至 2030 年的 $86.7 \%\left(2.753 \times 10^{6} \mathrm{t}\right)$, 化学磷肥占种植 

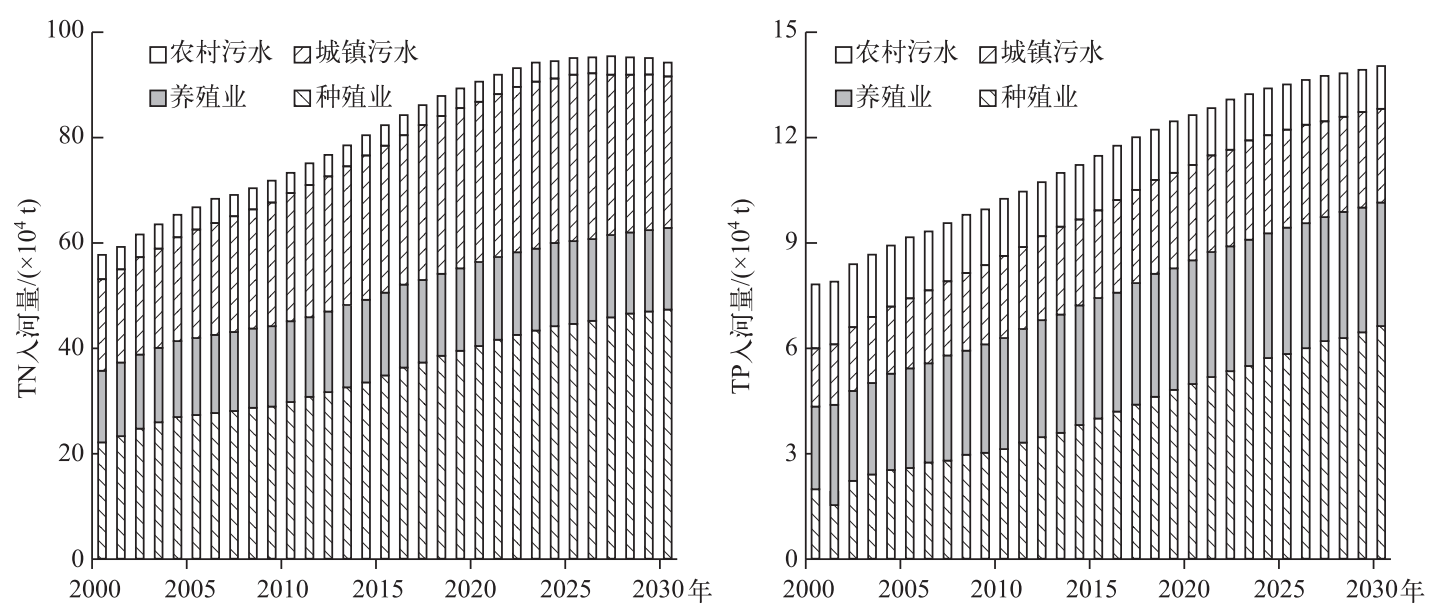

图 4 珠江流域 TN 和 TP 来源及其人河量的时间变化趋势

Fig.4 Source and temporal trend for TN and TP inputs in the Pearl River Basin

业磷污染的比例从 2000 年的 $71.7 \%\left(2.83 \times 10^{5} \mathrm{t}\right)$ 增加至 2030 年的 $87.9 \%\left(1.17 \times 10^{6} \mathrm{t}\right)$, 在对未来的模拟研 究中, 2013-2030 年间化学氮肥和磷肥施用量年均增速分别为 2.5\% 和 $4.1 \%$, 相比于 $2000-2012$ 年间增速 受到抑制 ( 分别为 $3.3 \%$ 和 $6.1 \%$ ), 故化肥施用量对种植业氮、磷营养盐污染量和变化趋势的影响最大; 其次 是堆肥施用量, 2000-2030 年间,堆肥的 TN 和 TP 施用量对相应种植业氮、磷污染的年均贡献率分别为 $10.5 \%$ 和 $19.6 \%$, 均出现先减少后增加的趋势, 至 2012 年最低 (TN 和 TP 施用量分别为 $1.48 \times 10^{5}$ 和 $7.30 \times 10^{4} \mathrm{t}$ ); 农作 物残体所占的比重次之, 其污染量与农作物产量呈正比, 受秸秆处理方式影响 ${ }^{[53]}$; 沼肥的 TN 和 TP 施用量 所占的比重最小, 而相应的贡献比率在 2000-2030 年间一直增加, TN 施用量从 2.3\% 增加至 7.6\%, TP 施用 量从 2.4\%增加至 9.0\% (图 5). 在有机粪肥的使用过程中, 由于规模化畜禽养殖的推广和沼气工程建设补贴 政策的实施, 越来越多养殖场利用沼气工程来处理粪污, 因此沼肥的生产量和使用量均有所增加; 另外养殖 场周边缺乏能够同时消纳堆肥和沼肥的农田, 且沼肥相对堆肥而言在储存和运输上具有较大的局限性, 故 一般情况下农户倾向于先使用沼肥, 从而导致堆肥的使用量出现一定程度的下降; 但随着有机肥的推广, 异 地生产和使用有机肥将变得更为容易, 所以未来堆肥和沼肥的使用量将会出现增加趋势 ${ }^{[54]}$. 珠江流域为了 满足粮食需求, 在农作物生产过程中过多施用化学肥料且伴随较低的化肥使用效率, 因此未来应提高珠江 流域化肥的使用效率, 并提高有机肥料的使用比例, 以改善土壤养分的流失状况, 进而达到提高农作物产量 和减少肥料造成的营养盐污染的目的.

畜禽养殖氮、磷营养盐污染主要是畜禽粪污通过储存和堆肥、直接排放和处理后排放三个环节进人环 境所引起的, 其中储存和堆肥以及直排流失的养分通过径流冲刷进人河流造成非点源污染. 2000-2030 年 储存和堆肥过程产生的 TN 和 TP 人河量均出现先下降再上升的趋势, 至 2012 年达到最低 (分别为 $3.0 \times 10^{4}$ 和 $0.6 \times 10^{4} \mathrm{t}$ ) ; 在畜禽养殖 TN 和 TP 人河量中所占的比重较为平稳, 年均贡献率分别为 $20.5 \%$ 和 $18.2 \%$ (图 6 ). 直接排放产生的 TN 人河量则从 2000 年的 $8.1 \times 10^{4} \mathrm{t}$ 持续下降至 2030 年的 $4.5 \times 10^{4} \mathrm{t}$, 所占畜禽养殖 TN 人河总量的年均贡献比例为 $42.5 \%$, 从 2016 年开始从畜禽养殖氮污染的最大贡献源变为第二大贡献源; 同 样, 直接排放产生的 TP 人河量由 2000 年的 $1.1 \times 10^{4} \mathrm{t}$ 减少至 2030 年的 $0.7 \times 10^{4} \mathrm{t}$, 所占畜萮养殖 TP 人河总 量的年均贡献比例为 $29.9 \%$, 并从 2005 年开始从畜禽磷污染最大贡献源变为第二大贡献源. 2000-2030 年 处理后排放的 TN 人河量呈现先增加后减少的趋势, 至 2027 年达到最大值 $\left(7.2 \times 10^{4} \mathrm{t}\right)$, 从 2016 年开始成为 畜禽养殖氮污染的最大贡献源, 年均贡献率为 $37.0 \%$; TP 人河量所占畜禽养殖 TP 人河总量的年均贡献比例 为 $52.0 \%$, 在 2025 和 2028 年分别出现波峰, 2005 年开始成为畜禽养殖磷污染的最大贡献源. 总体上来看, 2012 年后养殖场会继续朝着集约化、标准化和无害化的方向发展, 因此养殖场沼气工程和污水处理设施配 套比例将会继续提高, 这使得大量的养殖粪污通过沼气工程处理后转化为肥料, 也可以进一步经过污水处 

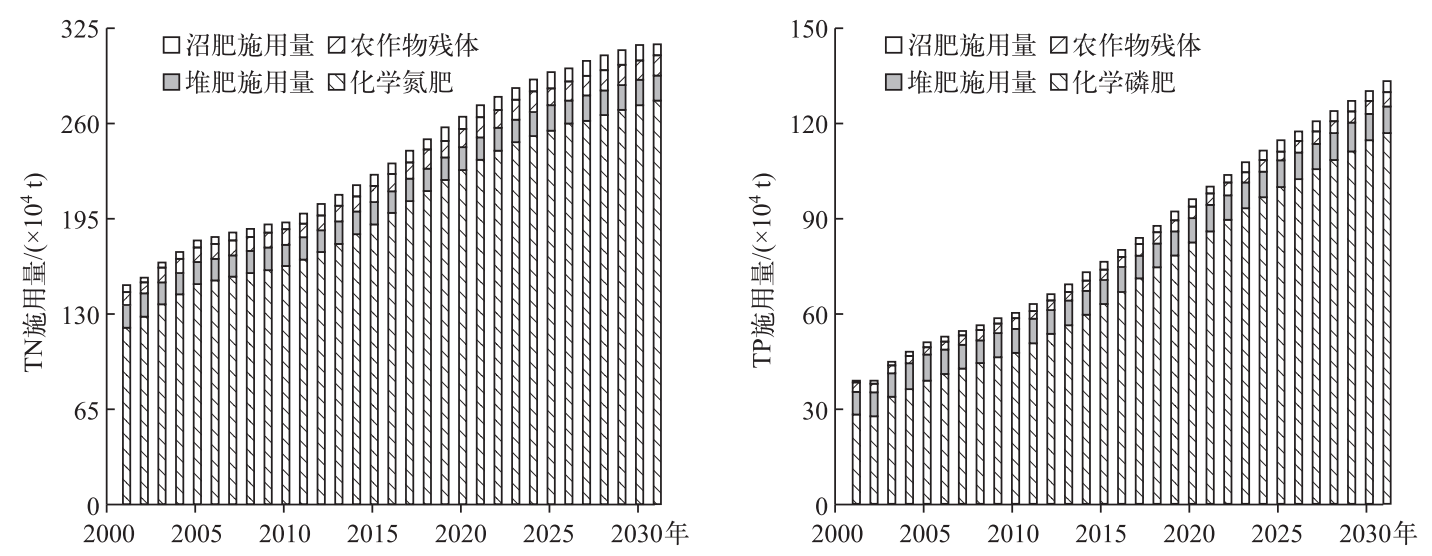

图 5 种植业 $\mathrm{TN}$ 和 TP 施用量的时间变化趋势

Fig.5 Temporal trends for quality of TN and TP application in planting industry

理设施处理后再排放, 从而大大减少了直接排放的污染量 ${ }^{[55]}$, 同时随着沼肥施用量的增加和污水处理水平 的进一步提高, 处理后排放的粪污量增长变缓甚至下降, 因此总体上畜禽养殖的氮、磷污染量相比其它污染 源更早到达增长饱和点. 此外, 本研究中 2000-2030 年畜禽粪污中氮养分的还田率从 $29.9 \%$ 提高至 $32.2 \%$, 磷养分的还田率则基本维持在 $42.5 \%$ 的水平, 这也是畜禽养殖污染量得以降低的一个重要原因.
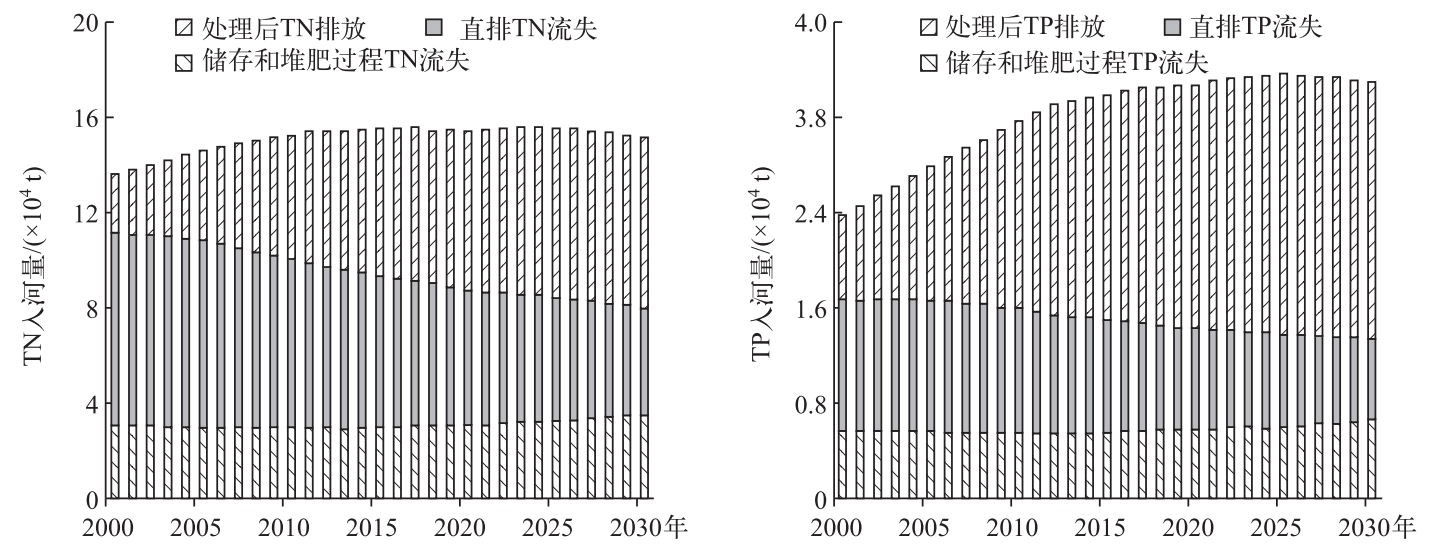

图 6 畜禽养殖业 TN 和 TP 人河量的时间变化趋势

Fig.6 Temporal trends for TN and TP inputs in livestock and poultry breeding

2000- 2030 年间,珠江流域城镇污水 TN 和 TP 产生量呈现递增趋势, 年均增长速度分别为 $5.6 \%$ 和 $4.4 \%$, 至 2030 年分别达到 $9.54 \times 10^{5}$ 和 $6.60 \times 10^{4} \mathrm{t}$; 农村污水 TN 和 TP 产生量呈现递减趋势, 年均下降速度均 为 $1.4 \%$, 至 2030 年分别达到 $1.42 \times 10^{5}$ 和 $1.40 \times 10^{4} \mathrm{t}$ (图 7). 主要原因为居民污水的营养盐产生量与经济发 展水平和城镇化率密切相关 ${ }^{[56]}, 2030$ 年 $\operatorname{GDP}(424500$ 亿元) 和城镇化率 $(75.0 \%)$ 相对 2000 年分别增加 5.4 和 1.6 倍,居民生活水平将大大提高.

\section{3 与其它研究的比较}

此前已有关于珠江流域营养盐污染和输出方面的研究. 在 $\mathrm{Ti}$ 等 ${ }^{[12]}$ 的研究中, $2000 、 2005$ 和 2010 年珠江 流域的 TN 人河总量分别为 $6.30 \times 10^{5} 、 7.41 \times 10^{5}$ 和 $7.70 \times 10^{5} \mathrm{t}$, 分别高于本研究 $8.8 \% 、 11.1 \%$ 和 $5.5 \%$, 主要原 因可能在于采用省域尺度的社会活动数据和考虑了氮的径流和淋溶损失. Strokal 等 ${ }^{[13]}$ 则估算了 $1970-$ 2050 年珠江流域子流域尺度不同污染源的溶解性无机氮 (DIN) 和溶解性无机磷 (DIP) 输出量, 研究发现: 至 

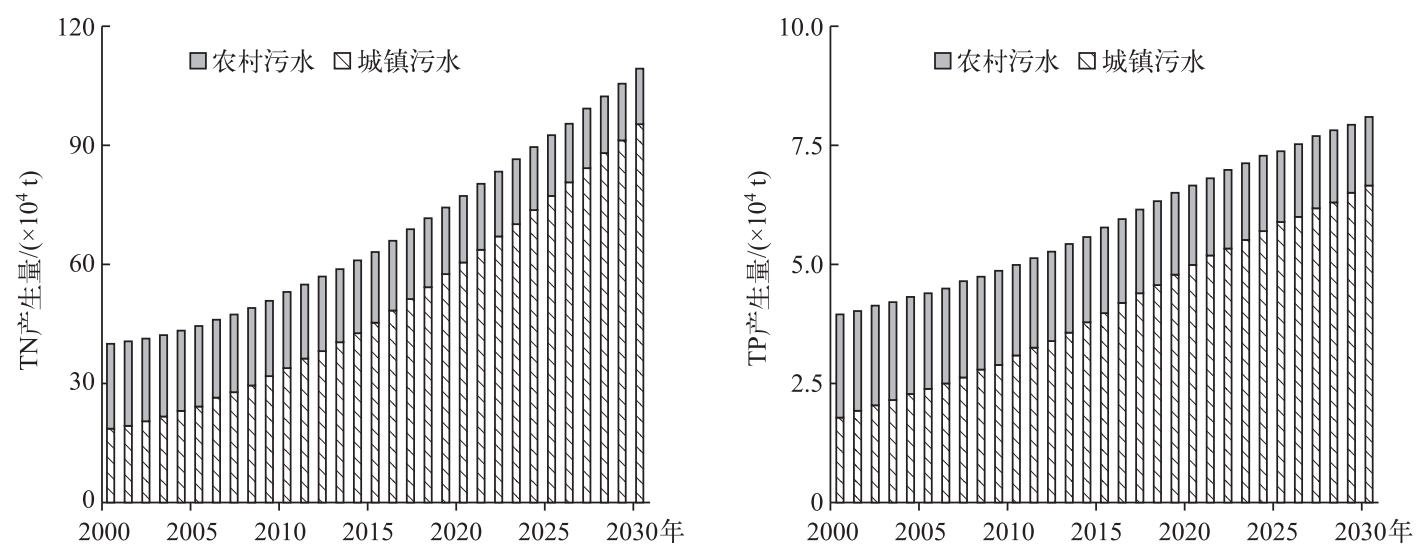

图 7 城镇和农村居民污水 TN 和 TP 产生量及其时间变化趋势

Fig.7 Discharge and temporal trend for TN and TP in municipal sewage and rural domestic wastewater

2000 年,农业源 DIN 输人到近海水域的贡献将近 $2 / 3$, 和本研究农业源对 TN 人河量贡献趋势接近 $(62.1 \%)$; 在 1970-2000 年, DIP 输人从 $0.3 \times 10^{4} \mathrm{t}$ 增加到 $0.5 \times 10^{4} \mathrm{t}$ 且可能会继续增加, 主要可能在于化肥 施用和城镇污水排放增加导致,这与本研究结果一致. Tong 等 ${ }^{[10]}$ 利用 2006-2012 年珠江河口每月 TN 和 $\mathrm{TP}$ 监测数据, 估算的珠江进人近海水域的 TN 和 TP 量分别约为本研究的 1.1 和 0.3 倍, 相比于模型计算数 据, 其结果波动性较大, 受监测站点位置和径流量影响, 此外, 本研究模型输人数据及相关参数也存在不确 定性;然而,整体变化趋势与本研究大体一致.

\section{3 结论与展望}

本研究在基准情景下的模拟结果显示, 珠江流域 TN 总人河量在 2027 年达到峰值; 种植业贡献最多, 其 次是城镇污水、养殖业和农村污水. 珠江流域 TP 总人河量逐年递增,年均增长速度为 $2.0 \%$, 从 2018 年开始 缓慢增长; 2000-2010 年, 养殖业为第一污染源, 其次是种植业、城镇污水和农村污水;2011 年种植业的贡 献比例开始超过养殖业成为首要污染源. 在主要污染源中,珠江流域 2013-2030 年间化学氮肥和磷肥施用 量年均增速分别为 $2.5 \%$ 和 $4.1 \%$, 相应种植业 2030 年 TN 和 TP 人河量分别增加到 $4.77 \times 10^{5}$ 和 $6.70 \times 10^{4} \mathrm{t}$; $2013-2030$ 年间畜禽养殖量增加了 $22.9 \%$, 相应养殖业 2030 年 TN 和 TP 人河量分别增加到 $1.52 \times 10^{5}$ 和 $3.50 \times 10^{4} \mathrm{t}$; 未来珠江流域应提高化肥的使用效率, 并提高有机肥料的使用比例, 以改善土壤养分的流失状 况,进而达到提高农作物产量和减少肥料造成的营养盐污染的目的.

珠江流域氮、磷营养盐人河量整体呈现上升趋势, 对流域水体安全依然构成极大的威胁. 其主要污染源 为农业非点源, 但在农业生产中现代农业生产要素和传统农业方式并存, 即表现为对化肥、农药等现代农业 生产要素依赖性增强和农户缺乏在使用现代生产要素过程中的科学指导,农户依然维持小规模生产、低市 场化的传统生产理念. 故农业非点源受农户生产行为、农业管理措施和农业政策等因素的影响, 为了从根本 上控制营养盐污染, 重视农户行为微观层面对流域营养盐污染宏观层面的影响, 将在下一篇文章中基于农 户个体行为政策情景分析来探讨未来珠江流域农业非点源营养盐污染的产生与控制政策.

\section{4 参考文献}

[ 1 ] Meng Wei, Liu Zhengtao, Zhang Nan et al. The study on technique of basin water quality target management ( II ): Water environmental criteria, standard and total amount control. Research of Environmental Sciences, 2008, (1) : 1-8. [孟伟, 刘征涛, 张楠等. 流域水质目标管理技术研究 (II ) 一一水环境基准、标准与总量控制. 环境科学研究, 2008, (1): 1-8.]

[ 2 ] Qian Yi, Liu Changming eds. Countermeasure of pollution prevention and mitigation of rivers and lakes in China. Beijing: China Water \& Power Press, 2002: 250. [ 钱易, 刘昌明. 中国江河湖海防污减灾对策. 北京: 中国水利水电出版社, 
2002: 250.]

[ 3 ] Li Le, Wang Shengrui, Wang Haifang et al. Temporal and spatial variations of phosphorus loading and the forms, compositions and contributions in inlet river of Lake Dianchi. J Lake Sci, 2016, 28( 5 ) : 951-960. DOI: 10.18307/2016.0504. [李乐, 王圣瑞, 王海芳等. 滇池人湖河流磷负荷时空变化及形态组成贡献. 湖泊科学, 2016, 28(5) : 951-960.]

[ 4 ] MOA ( Ministry of Agriculture of China), NBS ( National Bureau of Statistics of China), MEP (Ministry of Environment Protection of China) eds. The first national pollution census report. Beijing: MEP, 2010. [中华人民共和国农业部, 中 华人民共和国环境保护部，中华人民共和国国家统计局. 第一次全国污染源普查公报. 北京: 中华人民共和国国 家统计局, 2010.]

[ 5 ] Ma L, Velthof GL, Wang FH et al. Nitrogen and phosphorus use efficiencies and losses in the food chain in China at regional scales in 1980 and 2005. Science of the Total Environment, 2012, 434(SI) : 51-61.

[ 6 ] Powers SM, Bruulsema TW, Burt TP et al. Long-term accumulation and transport of anthropogenic phosphorus in three river basins. Nature Geoscience, 2016, 9(5) : 353.

[ 7 ] Mueller ND, Gerber JS, Johnston M et al. Closing yield gaps through nutrient and water management. Nature, 2012,490 (7419): 254-257.

[ 8 ] Ju XT, Gu BJ, Wu YY et al. Reducing China's fertilizer use by increasing farm size. Global Environmental Change, 2016, 41: 26-32.

[ 9 ] Liu BJ, Chen JF, Lu WX et al. Spatiotemporal characteristics of precipitation changes in the Pearl River Basin, China. Theoretical and Applied Climatology, 2016, 123(3/4) : 537-550.

[10] Tong YD, Zhao Y, Zhen GC et al. Nutrient Loads Flowing into Coastal Waters from the Main Rivers of China (20062012). Scientific Reports, 2015, 5(16678).

[11] Huang XP, Huang LM, Yue WZ. The characteristics of nutrients and eutrophication in the Pearl River estuary, South China. Marine Pollution Bulletin, 2003, 47(1-6) : 30-36.

[12] Ti CP, Yan XY. Spatial and temporal variations of river nitrogen exports from major basins in China. Environmental Science and Pollution Research, 2013, 20(9): 6509-6520.

[13] Strokal M, Kroeze C, Li LL et al. Increasing dissolved nitrogen and phosphorus export by the Pearl River (Zhujiang) : A modeling approach at the sub-basin scale to assess effective nutrient management. Biogeochemistry, 2015, 125(2): 221-242.

[14] Qu HJ, Kroeze C. Past and future trends in nutrients export by rivers to the coastal waters of China. Science of the Total Environment, 2010, 408(9): 2075-2086.

[15] Xie Lichun, Chen Jianyao. Nitrogen budgets of Pearl River Delta and its regional differences during the past decade. Journal of Natural Resources, 2014, 29(2): 237-248. [谢丽纯, 陈建耀. 近 10 a 来珠江三角洲地区氮收支演变及区域差 异分析. 自然资源学报, 2014, 29(2): 237-248.]

[16] Qu HJ, Kroeze C. Nutrient export by rivers to the coastal waters of China: Management strategies and future trends. Regional Environmental Change, 2012, 12(1): 153-167.

[17] Strokal M, Yang H, Zhang YC et al. Increasing eutrophication in the coastal seas of China from 1970 to 2050. Marine Pollution Bulletin, 2014, 85(1): 123-140.

[18] Yu D, Yan WJ, Chen NW et al. Modeling increased riverine nitrogen export: Source tracking and integrated watershedcoast management. Marine Pollution Bulletin, 2015, 101(2): 642-652.

[19] Li Xinyan, Yang Libiao, Yan Weijin. Scenario prediction and sensitivity of modeling dissolved inorganic phosphorous export from the Yangtze River. J Lake Sci, 2011, 23(2) : 163-173. DOI:10.18307/2011.0202. [李新艳, 杨丽标, 晏维 金. 长江输出溶解态无机磷的通量模型灵敏度分析及情景预测. 湖泊科学, 2011, 23(2): 163-173.]

[20] Chen Fajin, Jia Guodong. Nitrogen budgets of the Beijiang River Basin. Tropical Geography, 2009, 29(1): 11-15. [ 陈法 锦, 贾国东. 北江流域氮收支估算. 热带地理, 2009, 29(1): 11-15.]

[21] Liu Xiaochen, Li Xiaoping, Chen Xiaohua et al. Reduction strategies for TN and TP based on system dynamics model (SD) in Lake Erhai. J Lake Sci, 2013, 25(5) : 655-664. DOI:10.18307/2013.0506. [ 刘晓臣, 李小平, 陈小华等. SD 模型在洱海流域营养物削减策略研究中的应用. 湖泊科学, 2013, 25(5): 655-664.]

[22] Zhong Yongguang, Jia Xiaojing, Qian Ying et al eds. System dynamics. Beijing: Science Press, 2013: 303 . [ 钟永光, 贾 晓菁, 钱颖等. 系统动力学. 北京: 科学出版社, 2013: 303.] 
[23] Gao W, Hong B, Swaney DP et al. A system dynamics model for managing regional N inputs from human activities. Ecological Modelling, 2016, 322: 82-91.

[24] Wang S, Xu L, Yang FL et al. Assessment of water ecological carrying capacity under the two policies in Tieling City on the basis of the integrated system dynamics model. Science of the Total Environment, 2014, 472: 1070-1081.

[25] Wu Wei, Wu Song, Chen Shuang. Development pattern of Lake Poyang Region based on the system dynamic model. $J$ Lake Sci, 2012, 24(2): 252-258. DOI:10.18307/2012.0213. [ 吴威, 吴松, 陈爽. 基于 SD 模型分析的环鄱阳湖地 区发展模式探讨. 湖泊科学, 2012, 24(2): 252-258.]

[26] Hou Xikang, Gao Wei, Xu Peng et al. Impacts of watershed socio-economic development on Lake Dongping ecosystems of Shandong Province: Assessment and joint-mitigation. J Lake Sci, 2014, 26(2) : 313-321. DOI : 10. 18307/2014.0219. [后希康, 高伟, 徐鹏等. 流域社会经济发展对山东省东平湖水环境影响评估及优化调控. 湖泊科学, 2014,26 (2): 313-321.]

[27] Osmond DL, Hoag DLK, Luloff AE et al. Farmers' use of nutrient management: Lessons from watershed case studies. Journal of Environmental Quality, 2015, 44(2) : 382-390.

[28] Lai CG, Chen XH, Wang ZL et al. Spatio-temporal variation in rainfall erosivity during 1960-2012 in the Pearl River Basin, China. Catena, 2016, 137: 382-391.

[29] Xu Peng, Lin Yonghong, Luan Shengji. Policies scenario analysis from the perspective of farmers' individual behavior for nitrogen and phosphorous nutrient controlling of Pearl River Basin. J Lake Sci, 2018, 30(1). [徐鹏, 林永红, 奕胜基. 基于农户个体行为的珠江流域氮、磷营养盐控制政策情景分析. 湖泊科学, 2018, 30(1).]

[30] Qin Yaochen, Zhao Bingdong, Zhang Junjun et al. System dynamic modeling and regulation for regional sustainable development: An example of Henan Province. Systems Engineering-Theory \& Practice, 1997, 17(7) : 126-133. [秦耀辰, 赵 秉栋, 张俊军等. 河南省持续发展系统动力学模拟与调控. 系统工程理论与实践, 1997, 17(7): 126-133.]

[31] Li Lili. Simulation of nutrients export by rivers from watersheds and management policy scenario analysis: Case study of a Pearl River Sub-basin [Dissertation]. Beijing: Peking University, 2014. [李丽丽. 流域营养盐输出模拟及控制政策情 景分析一一以珠江支流为例 [ 学位论文]. 北京: 北京大学, 2014.]

[32] Wang Lan. Research on agriculture inland phenomenon under environmental and resource restriction[Dissertation]. Beijing: Peking University, 2015. [ 汪岗. 我国农业内陆化现象研究——基于资源环境视角 [学位论文]. 北京: 北京大 学, 2015.]

[33] Gao Wei. Agri-environmental policy assessment method research based on farm household scale [Dissertation]. Beijing: Peking University, 2015. [ 高薇. 基于农户尺度的农业环境政策评估方法研究 [学位论文]. 北京: 北京大 学, 2015.]

[34] Jia Wei. Studies on the evaluation of nutrient resources derived from manure and optimized utilization in arable land of China [Dissertation]. Beijing: China Agricultural University, 2014. [贾伟. 我国粪肥养分资源现状及其合理利用分析 [学位论文]. 北京: 中国农业大学, 2014.]

[35] Tu Guoping. Research on agriculture energy circular economy of Jiangxi based on system dynamics[Dissertation ]. Nanchang: Nanchang University, 2005. [涂国平. 基于系统动力学的江西省农业能源循环经济系统研究 [学位论文]. 南昌: 南昌大学, 2005.]

[36] Han Hongyun, Yang Zengxu, Cai Shukai eds. A Study on policy design and options of agricultural non-point pollution control. Hangzhou: Zhejiang University Press, 2014: 321. [韩洪云, 杨曾旭, 蔡书楷. 农业面源污染治理政策设计与选 择研究. 杭州: 浙江大学出版社, 2014: 321.]

[37] Liu Jianguo. Research on prevention and control system of livestock and poultry excreta[Dissertation]. Nanjing: Nanjing Agricultural University, 2009. [柳建国. 畜离粪便污染的农业系统控制模拟及系统防控对策 [学位论文]. 南京: 南 京农业大学, 2009.]

[38] Jia Renan, Wang Cuixia, Tu Guoping et al eds. System dynamic feedback hierarchy complexity analyze of scale livestock breeding ecology energy engineering. Beijing: Science Press, 2007: 319. [贾仁安, 王翠霞, 涂国平等. 规模养种生态 能源工程反馈动态复杂性分析. 北京: 科学出版社, $2007: 319$. ]

[39] Wang Wei, Sun Yanbin, Zhou Qi et al. A review on irrigation of biogas slurry from livestock manure anaerobic fermentation in China. China Biogas, 2015, 33(2) : 51-57. [王玮, 孙岩斌, 周祺等. 国内畜离厌氧消化沼液还田研究进展. 中国 沼气, 2015, 33(2): 51-57.]

[40] Sui Qianwen, Dong Hongmin, Zhu Zhiping et al. Present status of biogas effluent treatment technology research and appli- 
cation. Journal of Agricultural Science and Technology, 2011, 13(1) : 83-87. [ 隋倩雯, 董红敏, 朱志平等. 沼液深度 处理技术研究与应用现状. 中国农业科技导报, 2011, 13(1): 83-87.]

[41] IPCC: 2006. IPCC Guidelines for National Greenhouse Gas Inventories: Volume 4 Agriculture, Forestry and Other Land Use. National Greenhouse Gas Inventories Programme, IGES, Japan, 2006.

[42] Van Drecht G, Bouwman AF, Knoop JM et al. Global modeling of the fate of nitrogen from point and nonpoint sources in soils, groundwater, and surface water. Global Biogeochemical Cycles, 2003, 17(11154).

[43] Lu Yifeng, Li Zongxun, Lei Baokun. status and assessment of fertilizing the nitrogen fertilizer and phosphatic fertilizer to the field in Dianchi Watershed. Yunnan Environmental Science, 2003, 22(1):34-37. [陆轶峰, 李宗逊, 雷宝坤. 滇池 流域农田氮、磷肥施用现状与评价. 云南环境科学, 2003, 22(1): 34-37.]

[44] Li Kaiming, Chen Zhongying, Jiang Qiang eds. Pollution characteristic and eco-environment responses in the Pearl River Estuary and adjacent area. Beijing: China Architecture \& Building Press, 2011: 286. [李开明, 陈中颖, 姜强. 珠江口 及毗邻海域污染特征及生态环境响应研究. 北京: 中国建筑工业出版社, 2011: 286.]

[45] Chen Xue. The appliance of SD model in the pollution control planning of Ashi River Basin [Dissertation]. Harbin : Northeast Forestry University, 2010. [陈雪. SD 模型在阿什河流域水污染控制规划中的应用 [学位论文]. 哈尔滨: 东北 林业大学, 2010.]

[46] Chen Chao, Huang Dongfeng, Qiu Xiaoxuan et al. Survey and evaluation of agricultural non-point source pollution and prevention- and-cure countermeasures in middle and upriver of Minjiang Drainage Area. Journal of Agro-Environment Science, 2007, 26(S2) : 368-374. [陈超, 黄东风, 邱孝煊等. 闽江中上游流域农业面源污染调查评估及其防治技术探讨. 农业环境科学学报, 2007, 26(S2): 368-374.]

[47] Xing GX, Zhu ZL. Regional nitrogen budgets for China and its major watersheds. Biogeochemistry, 2002,57 ( 1 ): 405-427.

[48] Qian Xiuhong, Xu Jianmin, Shi Jiachun et al. Comprehensive survey and evaluation of agricultural nonpoint source pollution in Hang-Jia-Hu waternet plain. Journal of Zhejiang University: Agric \& Life Sci, 2002, 28(2): 31-34. [ 钱秀红, 徐 建民, 施加春等. 杭嘉湖水网平原农业非点源污染的综合调查和评价. 浙江大学学报: 农业与生命科学版, 2002, $\mathbf{2 8}(2): 31-34$.

[49] Ye Fei, Bian Xinmin. Evaluation of Jiangsu water pollution caused by agriculture based on equivalent standard pollution index method. Journal of Agro-Environment Science, 2005, 24(S1) : 137-140. [叶飞, 市新民. 江苏省水环境农业非点 源污染“等标污染指数”的评价分析. 农业环境科学学报, 2005, 24(S1) : 137-140.]

[50] Ou Weixin, Gao Jianhua, Yang Guishan. Estimation of nitrogen and phosphorus pollution loads from inland in the coastal zone of Yancheng, Jiangsu. Ecology and Environment, 2006, 15(3): 495-498. [ 欧维新, 高建华, 杨桂山. 苏北盐城 海岸带陆源氮、磷污染负荷估算初探. 生态环境, 2006, 15(3) : 495-498.]

[51] Tao Ye, Xue Huifeng. A sustainable energy tax policy decision model based on investment willingness constraint. Computer Simulation, 2009, (4) : 312-316. [ 陶冶, 薛惠锋. 基于投资的可持续能源税收政策决策模型. 计算机仿真, 2009, (4) : 312-316.

[52] Yang Shunshun, Luan Shengji eds. Rural environmental management simulation based on the analysis of agricultural households' behavior. Beijing: Science Press, 2012: 201. [杨顺顺, 森胜基. 农村环境管理模拟: 农户行为的仿真分 析. 北京: 科学出版社, 2012: 201.]

[53] Gao Liwei, Ma Lin, Zhang Weifeng et al. Estimation of nutrient resource quantity of crop straw and its utilization situation in China. Transactions of the CSAE, 2009, 25(7) : 173-179. [高利伟, 马林, 张卫峰等. 中国作物秸秆养分资源数量 估算及其利用状况. 农业工程学报, 2009, 25(7): 173-179.]

[54] Yang Liping, Wang Yujun, Bai Youlu et al. Research focus and prospect for application of biogas residue to agricultural land. Journal of Agricultural Science and Technology, 2016, 18(3): 171-176. [杨俐苹, 王玉军, 白由路等. 农田施用 沼气残余物研究热点与展望. 中国农业科技导报, 2016, 18(3): 171-176.]

[55] Bai ZH, Ma L, Jin SQ et al. Nitrogen, phosphorus, and potassium flows through the manure management Chain in China. Environmental Science \& Technology, 2016, 50(24) : 13409-13418.

[56] Shan Ying, Zhang Wei, Li Dianbao et al. Distribution of nitrogen and phosphorus in medium and small rivers of Shanghai. Acta Ecologica Sinica, 2015, 35(15) : 5239-5247. [山鹰, 张玮, 李典宝等. 上海市不同区县中小河道氮、磷污染特 征. 生态学报, 2015, 35(15) : 5239-5247.] 